\title{
Social Media Used by Krishi Vigyan Kendra Scientists
}

\author{
Dishant Jojit James*, M. Shivamurthy, M. T. Lakshminarayan and S. Ganesamoorthi \\ Department of Agricultural Extension, University of Agricultural Sciences, Bangalore, India \\ *Corresponding author
}

\begin{abstract}
A B S T R A C T
The present study was undertaken in five southern states (Andhra Pradesh, Karnataka, Kerala, Tamil Nadu and Telangana) and two Union territories (Lakshadweep and Puducherry) of Southern India during 20192020 to find out the social media used by Krishi Vigyan Kendra scientists. One hundred and sixty one scientists working in 117 Krishi Vigyan Kendras were purposively selected as the sample of the study. The collected data was scored, tabulated and analysed using frequency, mean, standard deviation and multiple regression analysis. The results revealed that a majority of KVK scientists were very frequently using WhatsApp (91.93\%) and Facebook (61.49\%), while a majority of KVK scientists were not using Twitter (86.34\%), Quora (72.67\%), Telegram (68.94\%), Instagram $(66.46 \%)$ and Skype $(51.55 \%)$. A little more than one-third of the KVK scientists were: very frequently using YouTube (45.34\%), rarely using Messenger (36.02\%) and not using ResearchGate (41.61\%). It was found that more than three-fourth (79.51\%) of the KVK scientists were belonging to low to medium category of overall extent of utilization of social media. The important five informations disseminate by KVK scientists to the farmers were integrated pest management, date and venue of trainings/ demonstration, integrated nutrient management, availability of agricultural inputs and subsidies and integrated disease management. The $\mathrm{R}^{2}$ value indicated that all the 21 personal, socio-economic, psychological and communication characteristics of KVK scientists had contributed to the tune of 81.91 per cent of variation in using of social media by the KVK scientists. Poor internet connectivity in rural areas $(86.34 \%)$, lack of scientific validity in messages spread via social media $(80.75 \%)$, insufficiency of time to use social media for agricultural development (78.26\%), technical problems while using social media $(66.46 \%)$ and lack of privacy in social media $(54.04 \%)$ were the constraints faced by majority of KVK scientists while using social media.
\end{abstract}

\section{Keywords}

Extent of utilization, social media, scientists, Krishi Vigyan Kendra, constraints

\section{Article Info}

Accepted:

20 May 2020

Available Online:

10 June 2020

\section{Introduction}

There has been a phenomenal growth in the use of social media across the globe in the past decade. This can be attributed to the common platform social media provides to people to share their ideas and create their own content - be it texts, images, sound clips or videos and also the affordability of these platforms as they can be accessed without incurring extra charges. Convergence of technologies and evolution of multifunctional portable gadgets are other reasons for expanding social media reach.
Social media are contemporary channels of digital communication composed of various evolving tools for discussion and sharing of information among people. These digital tools include among others, Facebook, WhatsApp, You Tube, Twitter and Instagram.

Social media can be defined as a technosocial system for participatory culture, having characteristics like participation, openness, connectedness, conversation and community. This definition is based on the ideas set forward by Fuchs (2013) and Mayfield (2008). 
Social media sites gained their popularity not only because they connected friends and family but the huge potential of communication was soon realised and it started finding its use in professional communication. Content creation is faster through social media than traditional mass media channels of extension communication (Lucas, 2011).

In the agricultural sector too, there is an increasing rate of social media usage amongst stakeholders. Platforms like Facebook and WhatsApp are encouraging interaction among users and in sharing of information. Earlier, farmers used to exchange information and tips on farming when they got together at a meeting place in the village or depended on newspapers, television and radio for news. Today, farmers are using Facebook, Twitter and other tools to access news and also spread the news. Social media are empowering agricultural professionals and transforming agricultural organisations. Sokoya et al., (2012) opined that there is growth in the utilization of social media among agricultural professionals, researchers and other stakeholders.

Social media have ensured quick delivery of information and feedback between the sender and receiver. It has become an effective way of ensuring successful delivery and sustainability for the agricultural extension subsector. In India, the scientists of Krishi Vigyan Kendras play a pro-active role in transferring latest technologies with beneficial impacts to the farmers at grassroots level. Social media provides tools for them to share information and to be a part of discussions and debates on agriculture. It also helps them to be aware of the ongoing developments in the agriculture sector and stay updated. The agricultural scientists of KVKs have to organise trainings, communicate with farmers and resource persons and constantly upgrade themselves with knowledge regarding latest agricultural technologies. Thus, there is a need to know the extent of utilization of social media by the KVK scientists for collection and dissemination of agricultural information to the farming community. Against this background, the present study was undertaken with the following specific objectives include to analyse the extent of utilization of social media by the agricultural scientists of Krishi Vigyan Kendras and find out the kind of information disseminated to the farmers by KVK scientists using social media. Also to know the extent of contribution of personal, socio-economic, psychological and communication characteristics of KVK scientists on their extent of utilization of social media. And to document the constraints faced by the KVK scientists while using social media.

\section{Materials and Methods}

The present study was conducted in five southern states (Andhra Pradesh, Karnataka,Kerala, Tamil Nadu and Telangana) and two Union territories (Lakshadweep and Puducherry) of Southern India during 2019-2020. One hundred and sixty one scientists working in 117 Krishi Vigyan Kendras were purposively selected as the sample of the study.

\section{Extent of utilization of social media (Dependent variable)}

A preliminary survey was conducted using Google forms to know the usage of social media by KVK scientists under the jurisdiction of University of Agricultural Sciences, Bengaluru, as well as from scientists working in other KVKs of Karnataka, Central Silk board, Institute for Social and Economic Change, Bengaluru, Indian Grassland and fodder Research institute, Jhansi and Central Institute for Cotton Research, Nagpur. Based on the preliminary survey, 11 social media platforms 
(Table 1) were selected for the study. Extent of utilization of social media is operationalized as the frequency of use of selected social media in the last five years, by the KVK scientists, for seeking and dissemination of agricultural information, besides using social media for sharing success stories, communicating with other organisations, seeking suggestions as well as for entertainment purpose. The scoring pattern followed for using the social mediaby the KVK scientists are as follows:

\begin{tabular}{|l|c|}
\hline \multicolumn{1}{|c|}{ Extent of use } & Score \\
\hline Not used & 0 \\
\hline $\begin{array}{l}\text { Very rarely } \\
\text { (Used at least once in } \quad 6\end{array}$ \\
months) \\
\hline $\begin{array}{l}\text { Rarely } \\
\text { (Used at least once in a } \\
\text { month) }\end{array}$ & 1 \\
\hline $\begin{array}{l}\text { Frequently } \\
\text { (Used at least once in a week) }\end{array}$ & 3 \\
\hline $\begin{array}{l}\text { Very frequently } \\
\text { (Used at least once a day) }\end{array}$ \\
\hline
\end{tabular}

Based on the total score, the respondents were classified into three categories namely 'low', 'medium' and 'high' by considering mean (17.52) and half standard deviation (3.31) as a measure of check.

\begin{tabular}{|l|c|c|}
\hline Category & Criteria & Score \\
\hline Low & $\begin{array}{c}<(\text { Mean }-1 / 2 \\
\text { SD })\end{array}$ & Below 14.22 \\
\hline Medium & $($ Mean $\pm 1 / 2$ SD $)$ & 14.22 to 20.83 \\
\hline High & $\begin{array}{c}>(\text { Mean }+1 / 2 \\
\text { SD })\end{array}$ & Above 20.83 \\
\hline
\end{tabular}

Information on personal, socio-economic, psychological and communication characteristics(independent variables) (Table 4) of KVK scientists was collected using a structured questionnaire with suitable scales. The type of information disseminated by
KVK scientists to the farmers and constraints faced by the KVK scientists while using social media was collected from the respondents using open ended questions. The collected data was scored, tabulated and analysed using frequency, mean, standard deviation and multiple regression analysis.

\section{Results and Discussion}

Extent of utilization of social media by KVK Scientists

The results in Table 1 reveal that a majority of KVK scientists wereusing a variety of social media such as, Facebook, WhatsApp, YouTube, Instagram, Twitter, Telegram, LinkedIn, Skype, Messenger, Quora and ResearchGatefor seeking and dissemination of agricultural information, sharing success stories, communicating with other organisations, seeking suggestions as well as for entertainment purpose.

However, a majority of KVK scientists were very frequently using WhatsApp (91.93\%) and Facebook $(61.49 \%)$, while a majority of KVK scientists were not using Twitter (86.34\%), Quora (72.67\%), Telegram $(68.94 \%)$, Instagram $(66.46 \%)$ and Skype $(51.55 \%)$.

A little more than one-third of the KVK scientists were: very frequently using YouTube $(45.34 \%)$, rarely using Messenger $(36.02 \%)$ and not using ResearchGate $(41.61 \%)$. WhatsApp and Facebook are very popular and are more suitable platforms for collection and dissemination of agricultural information; hence majority of KVK scientists have used WhatsApp and Facebook.

\section{Overall extent of utilization of social media by KVK Scientists}

A bird's eye view of Table 2 reveals that as high as 47.83 per cent of the KVK scientists 
were belonging to the category of medium users in overall extent of utilization of social media, whereas 31.68 and 20.49 per cent of the KVK scientists were low and high users of overall extent of utilization of social media, respectively. It can be inferred that more than three-fourth $(79.51 \%)$ of the KVK scientists were belonging to low to medium category of overall extent of utilization of social media.

Less and non-use of social media such as Twitter, LinkedIn, Quora, Telegram, Instagram, Messenger, ResearchGate and Skype are the reasons for the majority of KVK scientists belonging to low to medium category of overall extent of utilization of social media.

\section{Information disseminated to the farmers} by KVK scientists using social media

The information disseminated by KVK scientists to the farmers using social media is presented in Table 3. The results reveal that the information on integrated pest management (I rank), date and venue of trainings/ demonstrations (II rank), integrated nutrient management (III rank), availability of agricultural inputs and subsidies (IV rank), integrated disease management ( $\mathrm{V}$ rank),seed treatment (VI rank), soil and water conservation (VII rank), sowing/ transplanting (VIII rank),inter-cultivation (IX rank) and farming systems (X rank) were disseminated to the farmers by the KVK scientists in order of importance.

The information on climate/weather/ market forecast (XVI rank), herbicide application (XVII rank), self-help groups/famers interest groups (XVIII rank), labour availability (XIX rank), transportation of produce to market (XX rank) and soil testing (XXI rank) were disseminated to the farmers by the KVK scientists which occupied the last six ranks.
Extent of contribution of personal, socioeconomic, psychological and communication characteristics of KVK scientists on the extent of utilization of social media

The results in Table 4 presents the findings on extent of contribution of personal, socioeconomic, psychological and communication characteristics of KVK scientists on their extent of utilization of social media. The findings revealed that 17 out of 21 personal, socio-economic, psychological and communication characteristics of $\mathrm{KVK}$ scientists namely, education, job experience, job performance, achievement motivation, innovative proneness, scientific orientation, job involvement, organizational climate, competition orientation, awards/recognition received, abroad exposure/countries visited, field activities conducted, mass media participation, trainings received, number of publications and participation in seminars/conferences had contributed significantly towards using more of social media by the KVK scientists. The $\mathrm{R}^{2}$ value indicated that all the personal, socioeconomic, psychological and communication characteristics of KVK scientists had contributed to the tune of 81.91 per cent of variation in using the social media by the KVK scientists.

Constraints faced by the Krishi Vigyan Kendra scientists while using social media

Poor internet connectivity in rural areas $(86.34 \%)$, lack of scientific validity in messages spread via social media $(80.75 \%)$, insufficiency of time to use social media for agricultural development (78.26\%), technical problems while using social media $(66.46 \%)$ and lack of privacy in social media $(54.04 \%)$ were the constraints faced by majority of KVK scientists while using social media (Table 5). Less than half of the KVK 
scientists faced constraints such as: lack of training on social media (45.34\%), absence of workplace policies regarding social media $(40.37 \%)$, lack of clarity regarding exact benefits of social media $(33.54 \%)$, use of basic mobile phones byfarmers (30.43\%), scarceness of social media content and groups related to agriculture (26.09\%), paucity of technically competent staff in KVKs, to use social media $(19.88 \%)$ and power fluctuations in rural areas $(13.04 \%)$ while using the social media.

Table.1 Extent of utilization of social media by KVK scientists ( $\mathrm{n}=161$ )

\begin{tabular}{|c|c|c|c|c|c|c|c|c|c|c|c|}
\hline \multirow{3}{*}{$\begin{array}{l}\text { Sl. } \\
\text { No. }\end{array}$} & \multirow[t]{3}{*}{ Social media } & \multicolumn{10}{|c|}{ Extent of utilization } \\
\hline & & \multicolumn{2}{|c|}{ Very frequently } & \multicolumn{2}{|c|}{ Frequently } & \multicolumn{2}{|c|}{ Rarely } & \multicolumn{2}{|c|}{ Very rarely } & \multicolumn{2}{|c|}{ Not used } \\
\hline & & No. & $\%$ & No. & $\%$ & No. & $\%$ & No. & $\%$ & No. & $\%$ \\
\hline 1. & Face book & 99 & 61.49 & 25 & 15.53 & 17 & 10.56 & 11 & 6.83 & 9 & 5.59 \\
\hline 2. & WhatsApp & 148 & 91.93 & 1 & 0.62 & 9 & 5.59 & 3 & 1.86 & 0 & 0.00 \\
\hline 3. & You Tube & 73 & 45.34 & 42 & 26.09 & 44 & 27.33 & 2 & 1.24 & 0 & 0.00 \\
\hline 4. & Instagram & 20 & 12.42 & 16 & 9.94 & 17 & 10.56 & 1 & 0.62 & 107 & 66.46 \\
\hline 5. & Twitter & 4 & 2.48 & 8 & 4.97 & 9 & 5.59 & 1 & 0.62 & 139 & 86.34 \\
\hline 6. & Telegram & 0 & 0.00 & 12 & 7.45 & 13 & 8.07 & 25 & 15.53 & 111 & 68.94 \\
\hline 7. & LinkedIn & 12 & 7.46 & 0 & 0.00 & 37 & 22.98 & 37 & 22.98 & 75 & 46.58 \\
\hline 8. & Skype & 5 & 3.11 & 11 & 6.83 & 33 & 20.50 & 29 & 18.01 & 83 & 51.55 \\
\hline 9. & Messenger & 4 & 2.48 & 24 & 14.91 & 58 & 36.02 & 32 & 19.88 & 43 & 26.71 \\
\hline 10. & Quora & 0 & 0.00 & 3 & 1.86 & 25 & 15.53 & 16 & 9.94 & 117 & 72.67 \\
\hline 11. & ResearchGate & 20 & 12.42 & 25 & 15.53 & 49 & 30.43 & 0 & 0.00 & 67 & 41.61 \\
\hline
\end{tabular}

Table.2 Overall extent of utilization of social media by KVK scientists $(n=161)$

\begin{tabular}{|c|c|c|c|}
\hline \multirow[t]{2}{*}{ SI.No. } & \multirow[t]{2}{*}{ Categories } & \multicolumn{2}{|c|}{ KVK Scientists } \\
\hline & & Number & Per cent \\
\hline 1. & Low $(<14.22$ score $)$ & 51 & 31.68 \\
\hline 2. & Medium (14.22 - 20.83 score) & 77 & 47.83 \\
\hline 3. & High ( >20.83 score ) & 33 & 20.49 \\
\hline & Total & 161 & 100.00 \\
\hline
\end{tabular}

Mean= $17.52 ;$ Standard deviation $=6.61$ 
Table.3 Information disseminated to the farmers by KVK scientists using social media ( $\mathrm{n}=161)$

\begin{tabular}{|c|c|c|c|}
\hline SI.No. & Information disseminated & Score & Rank \\
\hline 1 & Availability of agricultural inputs and subsidies & 278 & IV \\
\hline 2 & Agricultural machinery/ tools/ equipment & 220 & XIII \\
\hline 3 & Labour availability & 116 & XIX \\
\hline 4 & Land Preparation & 231 & XI \\
\hline 5 & Seed Treatment & 277 & V \\
\hline 6 & Sowing/ Transplanting & 243 & VIII \\
\hline 7 & Integrated nutrient management & 286 & III \\
\hline 8 & Integrated pest management & 289 & I \\
\hline 9 & Integrated disease management & 277 & V \\
\hline 10 & Herbicide application & 196 & XVII \\
\hline 11 & Inter-cultivation & 242 & IX \\
\hline 12 & Soil and water conservation & 276 & VII \\
\hline 13 & Harvesting and post-harvest management & 221 & XII \\
\hline 14 & Market demands/ avenues & 207 & $\mathrm{XV}$ \\
\hline 15 & Transportation of produce to market & 114 & $\mathrm{XX}$ \\
\hline 16 & Climate/weather/ market forecast & 197 & XVI \\
\hline 17 & Self-help groups/Famers interest groups & 159 & XVIII \\
\hline 18 & Agricultural development programmes & 219 & XIV \\
\hline 19 & Farming systems & 240 & $\mathrm{X}$ \\
\hline 20 & Date and venue of trainings/ demonstrations & 288 & II \\
\hline 21 & Soil testing & 43 & XXI \\
\hline
\end{tabular}


Table.4 Extent of contribution of personal, socio-economic, psychological and communication characteristics of KVK scientists on the extent of utilization of social media $(n=161)$

\begin{tabular}{|c|c|c|c|c|}
\hline $\begin{array}{l}\text { Sl. } \\
\text { No. }\end{array}$ & Independent Variables & $\begin{array}{l}\text { Regression } \\
\text { co-efficient }\end{array}$ & $\begin{array}{c}\text { SE of } \\
\text { regression } \\
\text { co-efficient }\end{array}$ & $\begin{array}{c}\text { 't' } \\
\text { value }\end{array}$ \\
\hline 1 & Age & 0.161 & 0.090 & $0.559^{\mathrm{NS}}$ \\
\hline 2 & Education & 0.328 & 0.921 & $2.807 * *$ \\
\hline 3 & Rural urban background & 0.261 & 0.121 & $0.463^{\mathrm{NS}}$ \\
\hline 4 & Job experience & 0.345 & 0.861 & $2.495^{*}$ \\
\hline 5 & Job satisfaction & 0.899 & 0.769 & $0.855^{\mathrm{NS}}$ \\
\hline 6 & Job performance & 0.225 & 0.561 & $2.493 *$ \\
\hline 7 & Achievement motivation & 0.196 & 0.469 & $2.392 *$ \\
\hline 8 & Innovative proneness & 0.259 & 0.518 & $2.000 *$ \\
\hline 9 & Scientific orientation & 0.264 & 0.666 & $2.522 *$ \\
\hline 10 & Perceived work load & 0.369 & 0.212 & $0.574^{\mathrm{NS}}$ \\
\hline 11 & Job involvement & 0.320 & 0.712 & $2.225^{*}$ \\
\hline 12 & e-readiness & 0.255 & 0.612 & $2.400 *$ \\
\hline 13 & Organizational climate & 0.258 & 0.592 & $2.295^{*}$ \\
\hline 14 & Competition Orientation & 0.283 & 0.692 & $2.445^{*}$ \\
\hline 15 & Awards/ recognition received & 0.266 & 0.592 & $2.226^{*}$ \\
\hline 16 & Abroad exposure/ countries visited & 0.242 & 0.498 & $2.057 *$ \\
\hline 17 & Field activities conducted & 0.348 & 0.812 & $2.333 *$ \\
\hline 18 & Mass media utilization & 0.397 & 0.792 & $1.994^{*}$ \\
\hline 19 & Trainings received & 0.288 & 0.868 & $3.013 * *$ \\
\hline 20 & Number of publications & 0.346 & 0.692 & $2.010^{*}$ \\
\hline 21 & Participation in seminars/ conferences & 0.207 & 0.501 & $2.421 *$ \\
\hline
\end{tabular}

NS=Non-significant, * Significant at 5 per cent level, ** Significant at 1 per cent level, $\mathrm{SE}=$ Standard Error; $\mathrm{R}^{2}=0.8191$ 
Table.5 Constraints faced by KVK Scientists while using social media $(n=161)$

\begin{tabular}{|c|c|c|c|}
\hline \multirow{2}{*}{$\begin{array}{l}\text { Sl. } \\
\text { no. }\end{array}$} & \multirow[t]{2}{*}{ Constraints* } & \multicolumn{2}{|c|}{ KVK scientists } \\
\hline & & Number & Per cent \\
\hline 1. & $\begin{array}{l}\text { Absence of workplace policies regarding social } \\
\text { media }\end{array}$ & 65 & 40.37 \\
\hline 2. & Poor internet connectivity in rural areas & 139 & 86.34 \\
\hline 3. & Technical problems while using social media & 107 & 66.46 \\
\hline 4. & $\begin{array}{l}\text { Scarceness of social media content and groups } \\
\text { related to agriculture }\end{array}$ & 42 & 26.09 \\
\hline 5. & $\begin{array}{l}\text { Paucity of technically competent staff in KVKs, } \\
\text { to use social media }\end{array}$ & 32 & 19.88 \\
\hline 6. & Lack of training on social media & 73 & 45.34 \\
\hline 7. & $\begin{array}{l}\text { Insufficiency of time to use social media for } \\
\text { agricultural development }\end{array}$ & 126 & 78.26 \\
\hline 8. & $\begin{array}{l}\text { Lack of clarity regarding exact benefits of social } \\
\text { media }\end{array}$ & 54 & 33.54 \\
\hline 9. & Lack of privacy in social media & 87 & 54.04 \\
\hline 10. & $\begin{array}{l}\text { Lack of scientific validity in messages spread via } \\
\text { social media }\end{array}$ & 130 & 80.75 \\
\hline 11. & Power fluctuations in rural areas & 21 & 13.04 \\
\hline 12. & Farmers use basic mobile phones & 49 & 30.43 \\
\hline
\end{tabular}

*Multiple response

The results revealed that a majority of KVK scientists were very frequently using WhatsApp (91.93\%) and Facebook (61.49\%) for seeking and dissemination of agricultural information, sharing success stories, communicating with other organisations, seeking suggestions as well as for entertainment purpose.

However, it was disheartening to note that majority of KVK scientists were not using Twitter (86.34\%), Quora (72.67\%), Telegram (68.94\%), Instagram (66.46\%) and Skype $(51.55 \%)$. Over three-fourth $(79.51 \%)$ of the KVK scientists were belonging to low to medium category of overall extent of utilization of social media. The KVK scientists need to be encouraged and trained by the Farm Universities, Indian Council of Agricultural Research institutes and other concerned agencies on the effective and efficient use of social media for timely dissemination of agricultural information to the farmers.

\section{References}

Fuchs, C. 2013, Social Media, A critical introduction, SAGE publications Limited.

Lucas, C.F., 2011, An analysis and recommendations of the use of social media within the Co-operative extension system: Opportunities, Risks and Barriers. Honors Thesis (Unpub.), College of Agriculture, Life Sciences and Social Sciences of Cornell University, United States of America.

Mayfield, A., 2008, What is Social Media? iCrossinghttp://www.icrossing.co.uk/file admin/uploads/eBooks/What_is_Social_ Media_iCrossing_ebook.pdf.

Sokoya, A.A., Onifade, F.N. and Alabi, A.O., 2012, Connections and Networking: 
The Role of Social Media in Agricultural Research in Nigeria. Session: 205- Social Networking for Agricultural Research, Education, and
Extension Service: An International Perspective-Agricultural Libraries Special Interest Group : 23-28.

\section{How to cite this article:}

Dishant Jojit James, M. Shivamurthy, M. T. Lakshminarayan and Ganesamoorthi. S. 2020. Social Media Used by Krishi Vigyan Kendra Scientists. Int.J.Curr.Microbiol.App.Sci. 9(06): 2609-2617. doi: https://doi.org/10.20546/ijcmas.2020.906.317 